\title{
Concurrent Inguinal Hernia Repair During Robot-Assisted Transperitoneal Radical Prostatectomy: Single Center Experience
}

\author{
Fevzi Bedir (D) \\ Mehmet Sefa Altay (iD ${ }^{2}$ \\ Hüseyin Kocatürk (iD) \\ Banu Bedir (iD) ${ }^{3}$ \\ Nurullah Hamidi (iD ${ }^{4}$ \\ Abdullah Erdem Canda (iD ${ }^{5}$ \\ 'Department of Urology, Health Sciences \\ University, Erzurum Regional Training and \\ Research Hospital, Erzurum, Turkey; \\ ${ }^{2}$ Department of Urology, Private Buhara \\ Hospital, Erzurum, Turkey; ${ }^{3}$ Department \\ of Public Health, Aziziye District Health \\ Directorate, Erzurum, Turkey; \\ ${ }^{4}$ Department of Urology, Ankara \\ Oncology Training and Research \\ Hospital, Ankara, Turkey; ${ }^{5}$ Department of \\ Urology, School of Medicine, Koç \\ University Hospital, Istanbul, Turkey
}

Objective: To evaluate outcomes of concurrent inguinal hernia (IH) repair with mesh during transperitoneal robot-assisted radical prostatectomy (RARP).

Material and Methods: Data of 26 patients (31 procedures) undergoing IH repair concurrently with RARP between January 2017 and January 2020 were evaluated retrospectively. Patients' demographics, intraoperative and postoperative variables were recorded. Patients were assessed based on prostate-specific antigen recurrence, IH recurrence, mesh infection, seroma formation and groin pain quarterly in the first year, and every six month thereafter.

Results: The median age was 64.5 years in our population. IH was detected preoperatively in $46.2 \%$ of patients $(n=12)$ and intraoperatively in $53.8 \%(n=14)$. Twenty-one $(80.8 \%)$ patients (11 of them had right $\mathrm{IH}$ and 10 of them had left $\mathrm{IH}$ ) had unilateral hernias and 5 patients $(19.2 \%)$ had bilateral hernias. Twenty-three $(88.4 \%)$ IHs were direct, three $(11.6 \%)$ were indirect. The median operative time and estimated blood loss were 192.5 (range: 140250) min and 100 (range: 10-170) $\mathrm{mL}$, respectively. The median duration of IH repair, time of drainage, length of hospitalization, and catheterization were 32.5 (range: 14-40) min. 2 (range: 2-6) days, 6 (range: 5-8) days and 7 (range: 5-7) days, respectively. No perioperative complication due to RARP or IH repair was observed. During a median follow-up time was 18 months, no scrotal hematoma, seroma formation or mesh infection was identified.

Conclusion: IH repair performed during the same session at RARP is a safe and applicable procedure.

Keywords: hernia, mesh application, prostate cancer, robotic surgery

\section{Introduction}

Robot-assisted radical prostatectomy (RARP) is increasingly being performed in the treatment of prostate cancer $(\mathrm{PCa})$. Both $\mathrm{PCa}$ and inguinal hernia (IH) are frequently seen in the aging male. ${ }^{1} \mathrm{IH}$ is detected either at physical examination before the operation or incidentally during surgery. Studies have reported IH in 20 $32 \%$ of patients at preoperative imaging and detected intraoperatively in approximately $33 \%$. $^{2,3}$ Studies have reported four-fold higher rates of incidental detection of $\mathrm{IH}$ in patients undergoing radical prostatectomy (RP), and high success in treating $\mathrm{IH}$ in the same session. ${ }^{4-7}$ However, the prevalence of $\mathrm{IH}$ is known to be increased in patients undergoing $\mathrm{RP}^{4,8}$

Historically, the first IH repair during prostatectomy was performed with two incisions by McDonald and Huggins in 1949. ${ }^{9}$ Results for IH together with RP in the same session were reported in subsequent studies. ${ }^{3,10}$ With the increasing
Correspondence: Fevzi Bedir Department of Urology, Health Sciences University, Erzurum Regional Training and Research Hospital, Erzurum, Turkey

Tel +904422325327

Fax +904422325023

Email fevzibedir84@gmail.com 
frequency of RARP, IH repair in the same session has also become increasingly common. ${ }^{11-14}$

Two techniques have been described for IH repair with mesh application- total extra peritoneal (TEP) and trans abdominal preperitoneal (TAPP). In this study, we aimed to present our experience with concurrent $\mathrm{IH}$ repair during RARP with TAPP and suture alone technique.

\section{Materials and Methods}

Following receipt of ethical committee approval for this study (2020/14-151), we evaluated 150 patients who underwent RARP between January 2017 and January 2020 retrospectively. Twenty-six patients who underwent IH repair during RARP were included to the study. The diagnosis of IH was made by preoperative physical examination, imaging or intraoperative direct examination. We performed pelvic lymph node dissection in 3 patients. Both RARP and IH repair procedures were performed by the same surgeon (FB). The patients were informed about the study and provided consent to participate.

Patients' histories were taken, and their files were examined. All patients were informed in terms of repairing a concomitant IH identified either before or intraoperatively during the robotic prostate cancer surgery procedures. While informed consent was obtained from patients with preoperative $\mathrm{IH}$, intraoperative consent was obtained from firstdegree relatives of patients with intraoperative IH. Patients were assessed in terms of recurrence of IH at routine controls. Those who were unwilling to participate in the study or who did not adhere to the routine follow-up program, with active urinary tract infection before surgery, or with previous histories of $\mathrm{IH}$ repair were excluded from the study. Patients were informed about the postoperative study and their consent was obtained to participate.

All patients had sterile urinalysis and urine culture. Preoperative patient characteristics (age, body mass index), prostate-specific antigen (PSA), intra and postoperative parameters including pathological Gleason grade, prostate volume at RARP specimen, total operation time, estimated blood loss, time of hospitalization, catheterization and drainage were entered into database.

All IH repair procedures performed after ensuring of anastomosis leakage absence tested intraoperatively by distending the urinary bladder with sterile saline solution. IH repair was performed using primary sutures or mesh application technique. IHs in asymptomatic patients and in patients who had defects smaller than $2 \mathrm{~cm}$ repaired with primary suturing. Mesh application was used for patients who were symptomatic, who had direct hernias and/or had a defect greater than $2 \mathrm{~cm}$. In complicated patients, general surgery consultation was requested.

\section{Technique of IH Repairing with Mesh Application}

Polypropylene mesh (Paha ${ }^{\circledR}$ Altaylar Medical Ankara/ Turkey) was used in IH repair. The mesh was fixed in place using non-absorbable sutures. The surface of the mesh was covered with peritoneum in order to avoid bowel adhesions (Figure 1).

\section{Technique of IH Repairing with Primary Suturing}

After extensive preperitoneal dissection of the peritoneal leaves, the hernia sac was completely dissected. The weakened transverse fascia was pulled and the defect was closed with a barbed suture $3 / 0 \mathrm{~V}-\mathrm{Loc}^{\mathrm{TM}}$ (Covidien) via continuous suturing technique.

We have included an Edited Video of the surgical technique.

On postoperative day-7, when cystography revealed that no anastomosis leakage was present, the Foley catheter was removed.

Patients were invited to attend routine control every three months in the first year, and six monthly thereafter. PSA, IH recurrence, mesh infection, seroma formation, and groin pain were evaluated at follow-up periods. Hernia recurrence was evaluated according to physician's examination. Presence of symptoms including fever, hyperemia, swelling and groin pain considered as mesh infection. Ultrasound is available in our urology outpatient clinic and it is a part of routine urological examination. Each patient who admitted for control evaluation after surgery was checked with physical examination, urinary system ultrasound and pelvic ultrasound.

\section{Statistical Analysis}

Data analysis was performed on Statistical Package for the Social Science (IBM SPSS Corp.; Armonk, NY, USA) v20 for Windows software. Categorical variables were expressed as number and percentage, and numerical variables as mean plus standard deviation. $\mathrm{p}<0.05$ was regarded as statistically significant.

\section{Results}

The median age, body-mass index (BMI), preoperative PSA, and prostate volume of our populations were 64.5 

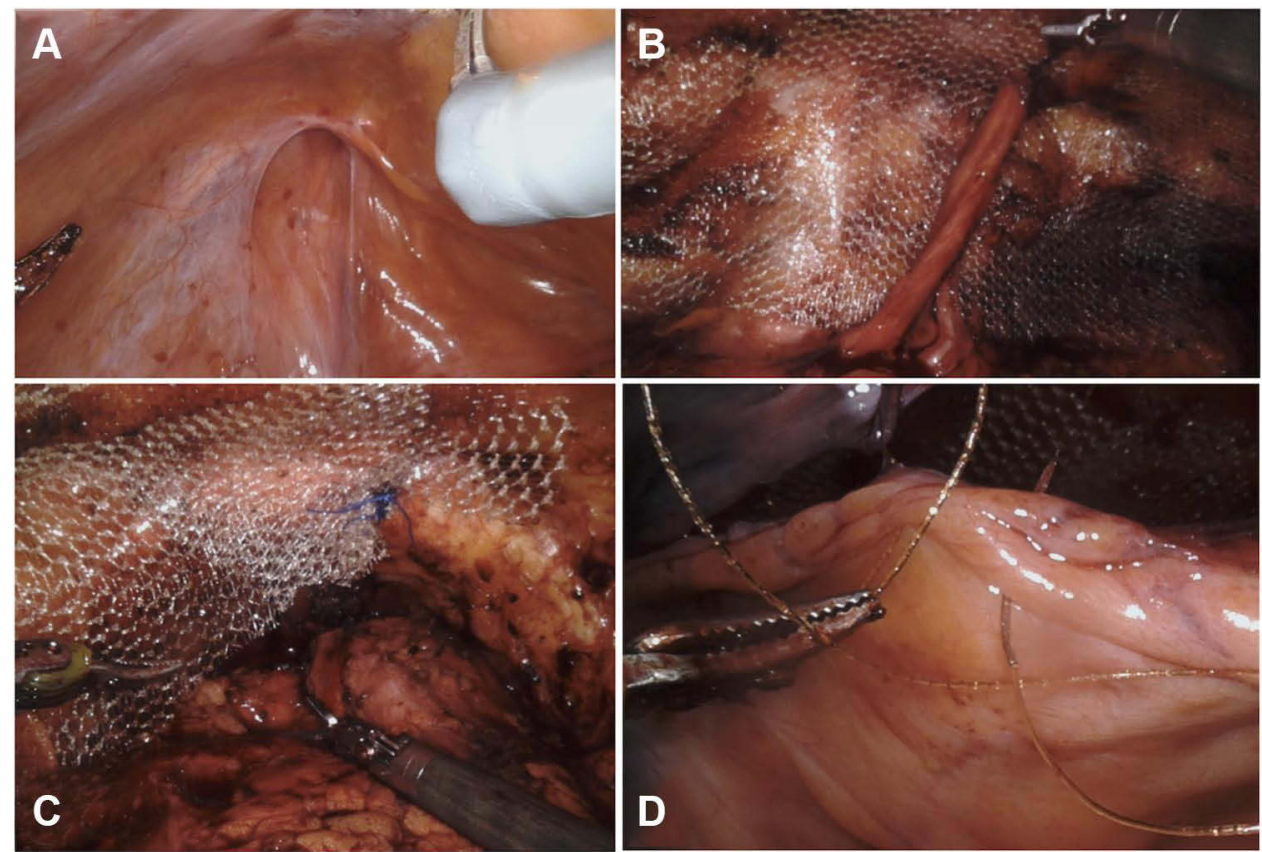

Figure I Unilateral indirect inguinal hernia repair during robot-assisted radical prostatectomy. Image of an indirect inguinal hernia fascia defect (A). Mesh application around the inguinal hernia defect (B). Mesh fixation to Cooper's ligament (C). Covering the mesh with peritoneum (D).

(range: 48-76) years, 28 (range: 21-35) $\mathrm{kg} / \mathrm{m}^{2}, 7.35$ (range: 2.9-15.1) $\mathrm{ng} / \mathrm{mL}$, and 92 (range: 32-240) cc, respectively. IH was detected preoperatively in $46.2 \%$ of patients $(\mathrm{n}=12)$ with physical examination and intraoperatively in $53.8 \%(\mathrm{n}=14)$. Unilateral IH was detected in $21(80.8 \%)$ patients (11 of them had right IH and 10 of them had left IH) whereas bilateral IH in 5 (19.2) patients. Twenty-three $(88.4 \%)$ IHs were direct whereas three (11.6\%) were indirect.

The median operative time and estimated blood loss were 192.5 (range: 140-250) min and 100 (range: 10
170) $\mathrm{mL}$. The median duration of IH repair, duration of drainage, length of hospitalization, and urethral catheterization were 32.5 (range: 14-40) min. 2 (range: 2-6) days, 6 (range: 5-8) days and 7 (range: 5-7) days, respectively. All patient demographics, intraoperative and postoperative variables were detailed in Table 1.

Median follow-up time was 18 months and we did not detect any scrotal hematoma, seroma formation and mesh infection during the follow-up periods. De-novo IH on the opposite of the repair site was detected during follow-up only in a patient.

Table I Demographics of All Patients and Operative Data

\begin{tabular}{|c|c|c|}
\hline Variables & Median (Minimum-Maximum) & Mean士 SD \\
\hline Age (years) & $64.5(48-76)$ & $63.2 \pm 7.2$ \\
\hline BMI $\left(\mathrm{kg} / \mathrm{m}^{2}\right)$ & $28(2 \mathrm{I}-35)$ & $27.2 \pm 3.6$ \\
\hline Preoperative PSA (ng/mL) & $7.35(2.9-15.1)$ & $7.43 \pm 2.3$ \\
\hline Postoperative PSA (ng/mL) & $0.009(0.00 \mathrm{I}-0.06)$ & $0.01 \pm 0.01$ \\
\hline Prostate volume (cc) & $92(32-240)$ & $99.3 \pm 49.8$ \\
\hline Duration of drainage (days) & $2.0(2-6)$ & $2.31 \pm 0.97$ \\
\hline Length of hospitalization (days) & $6.0(5-8)$ & $6.04 \pm 1.07$ \\
\hline Duration of catheterization (days) & $7.0(5-7)$ & $6.23 \pm 0.99$ \\
\hline Estimated blood loss ( $\mathrm{mL})$ & $100(10-170)$ & $93.4 \pm 48.6$ \\
\hline Total operative time (min) & $192.5(140-250)$ & $194.1 \pm 27.8$ \\
\hline Duration of IH repair (min) & $32.5(14-40)$ & $29.1 \pm 8$ \\
\hline
\end{tabular}

Note: *Statistically significant.

Abbreviations: BMI, body mass index; PSA, prostate-specific antigen; SD, standard deviation. 


\section{Discussion}

Inguinal hernia and PCa are frequently encountered diseases in older age. ${ }^{15}$ Therefore, these conditions can be seen concomitantly. Previous studies have reported that the rate of concomitant $\mathrm{IH}$ is $13-33 \%$ in patients during prostatectomy. ${ }^{3,15}$ On the other hand, several studies mentioned that the incidence of IH development is higher in patients who underwent RP compared than the normal population. $^{4,8}$ In our study, this rate was consistent with the literature. In addition, we believe that our patients' high prostate volumes and high average age increase this rate.

Adhesions occur in the surgical site following RP surgery, and complications such as organ and vascular injury may occur in secondary surgical procedures including IH repair following RP. In addition, IHs could be repaired in the same session with RP since they may become symptomatic in the postoperative period. Studies have shown that $\mathrm{IH}$ repair in the same session prolongs operative time by 45-111 min during laparoscopic or open RP, and by just 10-30 min during RARP. ${ }^{11-13,16,17}$ In our series, mean $\mathrm{IH}$ repair time was similar to the published literature. In addition, IH repair using minimally invasive techniques has been shown to cause less pain and to reduce length of hospital stay. ${ }^{18}$

The risk of mesh infection, postoperative inguinal pain, and adhesions are still unclear. ${ }^{19}$ Mesh fixation is recommended in order to prevent adhesions in IH repairs performed in the same session, together with the use of adhesion-resistant meshes. ${ }^{11-13,16,17,19}$ The risk of mesh infection might increase if anastomosis leakage is present. However, studies have revealed that RARP and IH repair in the same session is safe, with low complication rates. $^{11-14}$

The advantages of concomitant IH repair and RP surgeries are well known. Firstly, operation time for concurrent repair is shorter when compared both surgeries are performed separately. ${ }^{11,20}$ Secondly, performing a second surgery probably may cause additional comorbidities related to repeated anesthesia exposure to the patient. ${ }^{14}$ Thirdly and more important one, if the IH is not repaired concurrently during RP procedure, it might be more difficult to repair it via laparoscopic or robotic surgery due to possible preperitoneal space scarring in the following period after a previous RARP procedure. ${ }^{14,20}$

Theoretically, the risks of complication are expected to increase in operations where any prosthetic material is inserted. These risks arise from the possibility that the mesh material may contact with urine in the presence of vesico-urethral anastomosis leakage. ${ }^{14}$ Bedside surgeon and the nurse can change sterile gloves before handling the mesh and keep the mesh in its sterile box until it is time to use it to decrease the risk of mesh contamination. In addition, it should be kept in mind that placing a drain in the operation area may increase the risk of infection and should be removed as soon as possible. Another risk is adhesions of mesh to intraperitoneal structures like bowels. To decrease this risk, mesh could be covered with peritoneum (reperitonealization) or adhesionresistant coated mesh that might be more expensive could be used. ${ }^{14}$ Fortunately, such complications have not been found in previous studies. ${ }^{11,13,14}$ We used polypropylene monofilament meshes in all patients. In all cases, we closed the anterior peritoneum over the mesh for reducing bowel adhesion risk.

Another complication after IH repair is seroma formation. $^{21,22}$ The rate of seroma formation was reported to be between 1.9-22.9\% following laparoscopic IH repair in previous studies. ${ }^{21,22}$ On the contrary, several studies on concurrent IH repair with RARP reported no seroma formation. ${ }^{11,16,20,23}$ Prevention of seroma formation can be achieved with good hemostasis, drainage of surgical site fluids and fixing the mesh with a running absorbable suture to prevent formation of a dead space. ${ }^{24}$ We did not identify seroma formation in our series.

Lymphocele can develop especially in patients with prolonged lymphatic drainage due to performing extended pelvic lymph node dissection. ${ }^{14}$ Fortunately, the rate of development of lymphocele that need drainage during minimal invasive RP and concurrent $\mathrm{IH}$ repair was reported to be less than $5 \%$ in current literature. ${ }^{13,16} \mathrm{We}$ did not observe lymphocele development in our series. It may be due to the fact that we used endoclips instead of cautery application during performing lymph node dissection.

In our study, IH recurrence was not observed, however, IH developed at contralateral site only in a patient. This particular patient practiced intensive Kegel exercise and physical exercise in the early postoperative period that might have lead to increased abdominal pressure leading to $\mathrm{IH}$ formation. It has been reported that the recurrence rate is high in $\mathrm{IH}$ repairs without mesh. ${ }^{25}$

The principal limitations of our study include its retrospective nature, short follow-up period, and limited number of patients. 
$\mathrm{IH}$ and $\mathrm{PCa}$ are two common diseases and often seen together. Due to our experience, concomitant IH repair with a RARP procedure is safe, feasible, easy to perform with successful outcomes and acceptable complications.

\section{Ethics Committee Approval}

All procedures performed in studies involving human participants were in accordance with the ethical standards of the institutional and/or national research committee and with the 1964 Helsinki declaration and its later amendments or comparable ethical standards. Ethics committee approval was received for this study from the ethics committee of Health Sciences University, Erzurum Regional Training and Research Hospital (2020/14-151).

\section{Informed Consent}

Written informed consent was obtained from patients who participated in this study.

\section{Acknowledgments}

The authors declared that this study has received no financial support.

\section{Author Contributions}

All authors made a significant contribution to the work reported, whether that is in the conception, study design, execution, acquisition of data, analysis and interpretation, or in all these areas; took part in drafting revising or critically reviewing the article; gave final approval of the version to be published; have agreed on the journal to which the article has been submitted; and agree to be accountable for all aspects of the work.

\section{Disclosure}

Dr Abdullah Erdem Canda reports personal fees from Conmed, outside the submitted work. The authors report no other conflicts of interest in this work.

\section{References}

1. Lau H, Fang C, Yuen WK, Patil NG. Risk factors for inguinal hernia in adult males: a case-control study. Surgery. 2007;141(2):262-266. doi:10.1016/j.surg.2006.04.014

2. Fukuta F, Hisasue S, Yanase M, et al. Preoperative computed tomography finding predicts for postoperative inguinal hernia: new perspective for radical prostatectomy-related inguinal hernia. Urology. 2006;68(2):267-271. doi:10.1016/j.urology.2006.02.023

3. Nielsen ME, Walsh PC. Systematic detection and repair of subclinical inguinal hernias at radical retropubic prostatectomy. Urology. 2005;66 (5):1034-1037. doi:10.1016/j.urology.2005.05.028
4. Nilsson H, Stranne J, Stattin P, Nordin P. Incidence of groin hernia repair after radical prostatectomy: a population-based nationwide study. Ann Surg. 2014;259(6):1223-1227. doi:10.1097/SLA.0b013e3182975c88

5. Lin BM, Hyndman ME, Steele KE, et al. Incidence and risk factors for inguinal and incisional hernia after laparoscopic radical prostatectomy. Urology. 2011;77(4):957-962. doi:10.1016/j. urology.2010.12.011

6. Schlegel PN, Walsh PC. Simultaneous preperitoneal hernia repair during radical pelvic surgery. J Urol. 1987;137(6):1180-1183. doi:10.1016/S0022-5347(17)44441-7

7. Antunes AA, Dall'oglio M, Crippa A, Srougi M. Inguinal hernia repair with polypropylene mesh during radical retropubic prostatectomy: an easy and practical approach. BJU Int. 2005;96(3):330-333. doi:10.1111/j.1464-410X.2005.05626.x

8. Regan TC, Mordkin RM, Constantinople NL, Spence IJ, Dejter SW. Incidence of inguinal hernias following radical retropubic prostatectomy. Urology. 1996;47(4):536-537. doi:10.1016/S00904295(99)80491-9

9. McDonald DD, Huggins C. Simultaneous prostatectomy and inguinal herniorrhaphy. Surg Gynecol Obstet. 1949;89(5):621.

10. Stolzenburg JU, Rabenalt R, Dietel A, et al. Hernia repair during endoscopic (laparoscopic) radical prostatectomy. J Laparoendosc Adv Surg Techniq. 2003;13(1):27-31. doi:10.1089/109264203321235430

11. Finley DS, Savatta D, Rodriguez E, Kopelan A, Ahlering TE. Transperitoneal robotic-assisted laparoscopic radical prostatectomy and inguinal herniorrhaphy. J Robot Surg. 2008;1(4):269-272. doi:10.1007/s11701-007-0051-9

12. Joshi AR, Spivak J, Rubach E, Goldberg G, DeNoto G. Concurrent robotic trans-abdominal pre-peritoneal (TAP) herniorrhaphy during robotic-assisted radical prostatectomy. MRCAS. 2010;6(3):311-314. doi: $10.1002 / \mathrm{rcs} .334$

13. Ludwig WW, Sopko NA, Azoury SC, et al. Inguinal hernia repair during extraperitoneal robot-assisted laparoscopic radical prostatectomy. J Endourol. 2016;30(2):208-211. doi:10.1089/end.2015.0393

14. Atmaca AF, Hamidi N, Canda AE, Keske M, Ardicoglu A. Concurrent repair of inguinal hernias with mesh application during transperitoneal robotic-assisted radical prostatectomy: is it safe. Urol J. 2018;15(6):381-386. doi:10.22037/uj.v0i0.4158

15. Watson DS, Sharp KW, Vasquez JM, Richards WO. Incidence of inguinal hernias diagnosed during laparoscopy. South Med J. 1994;87 (1):23-25. doi:10.1097/00007611-199401000-00005

16. Do M, Liatsikos EN, Kallidonis P, et al. Hernia repair during endoscopic extraperitoneal radical prostatectomy: outcome after 93 cases. J Endourol. 2011;25(4):625-629. doi:10.1089/end.2010.0406

17. Forbes SS, Eskicioglu C, McLeod RS, Okrainec A. Meta-analysis of randomized controlled trials comparing open and laparoscopic ventral and incisional hernia repair with mesh. Br J Surg. 2009;96 (8):851-858. doi:10.1002/bjs.6668

18. HerniaSurge Group. International guidelines for groin hernia management. Hernia. 2018;22(1):1-165.

19. Kaler K, Vernez SL, Dolich M. Minimally invasive hernia repair in robot-assisted radical prostatectomy. $J$ Endourol. 2016;30 (10):1036-1040. doi:10.1089/end.2016.0225

20. Mourmouris P, Argun OB, Tufek I, et al. Nonprosthetic direct inguinal hernia repair during robotic radical prostatectomy. J Endourol. 2016;30(2):218-222. doi:10.1089/end.2015.0556

21. Morales-Conde S. A new classification for seroma after laparoscopic ventral hernia repair. Hernia. 2012;16(3):261-267. doi:10.1007/ s10029-012-0911-8

22. Cihan A, Ozdemir H, Uçan BH, et al. Fade or fate. Seroma in laparoscopic inguinal hernia repair. Surg Endosc. 2006;20 (2):325-328. doi:10.1007/s00464-005-0052-6

23. Qazi HA, Rai BP, Do M, et al. Robot-assisted laparoscopic total extraperitoneal hernia repair during prostatectomy: technique and initial experience. Central Eur J Urol. 2015;68(2):240-244. doi:10.5173/ceju.2015.562 
24. Birolini C, de Miranda JS, Utiyama EM, Rasslan S. A retrospective review and observations over a 16-year clinical experience on the surgical treatment of chronic mesh infection. What about replacing a synthetic mesh on the infected surgical field? Hernia. 2015;19 (2):239-246. doi:10.1007/s10029-014-1225-9
25. Vrijland WW, van den Tol MP, Luijendijk RW, et al. Randomized clinical trial of non-mesh versus mesh repair of primary inguinal hernia. $B r \quad J$ Surg. 2002;89(3):293-297. doi:10.1046/j.00071323.2001.02030.x

\section{Publish your work in this journal}

Robotic Surgery: Research and Reviews is an international, peer reviewed, open access, online journal publishing original research, commentaries, reports, and reviews on the theory, use and application of robotics in surgical interventions. Articles on the use of supervisorycontrolled robotic systems, telesurgical devices, and shared-control systems are invited. The manuscript management system is completely online and includes a very quick and fair peer review system, which is all easy to use. Visit http://www.dovepress.com/testimonials. php to read real quotes from published authors. 